\title{
Collision-Induced Oxygen Addition to Chloroaromatic Compounds
}

\author{
F. L. Lépine and S. Milot \\ Institut Armand-Frappier, Laval, Québec, Canada \\ D. Boismenu and O. A. Mamer \\ Biomedical Mass Spectrometry Unit, McGill University, Montréal, Québec, Canada
}

The reactions of chloroaromatic radical anions with oxygen were studied with a triple quadrupole mass spectrometer. Two chlorobenzenes and eight polychlorinated biphenyls were analyzed by gas chromatography-tandem mass spectrometry under negative ion chemical ionization. The molecular radical anions were selected with the first quadrupole and reacted with oxygen in the collision cell. Under these conditions, $[\mathrm{M}+\mathrm{O}-\mathrm{Cl}]$ ions were obtained with intensities similar to those of the transmitted precursor ions. This dechlorination reaction was not affected by a detectable chlorine isotope effect. The intensities of the $[\mathrm{M}+\mathrm{O}-\mathrm{Cl}]$ ions vary with the nature of the chloroaromatic compounds and with the oxygen pressure and collision energy. Charge transfer reactions are also observed, and the relative amount of $\mathrm{O}_{2}^{-}$produced is controlled by the relative electron affinity of the organochlorine. At high collision energies, collision-induced fragmentation of the molecular ion competes for the production of $\mathrm{Cl}^{-}$. (c) 1996 American Society for Mass Spectrometry (J Am Soc Mass Spectrom 1996, 7, 1144-1150)

$\mathrm{T}$ The electron capture negative ion (ECNI) mass spectra of many chlorinated compounds show ions at $\mathrm{M}-19$ [1-3]. These ions correspond to addition of one oxygen atom to the molecule with the loss of one chlorine atom. The reaction proceeds through addition of $\mathrm{O}_{2}$, which is present in trace amounts in the source, to the organochlorine to form an intermediate that subsequently loses $\mathrm{OCl}^{\circ}$ to produce an even electron [M $+\mathrm{O}-\mathrm{Cl}]$ anion [4]. Many investigators deliberately have introduced oxygen into the source to enhance these reactions to obtain substitution pattern information by using the molecular and other ions derived from many polychlorinated dibenzofurans [5] and dioxins [6]. Collision-induced dissociation (CID) experiments on the $[\mathrm{M}+\mathrm{O}-\mathrm{Cl}]$ ions of various polychlorinated biphenyls (PCBs) also were performed for the same purpose [7]. The toxicological properties of these pollutants vary with their substitution pattern, which is difficult to determine on a chromatographic basis alone.

In a previous publication we reported the regioselective dechlorination of PCBs in ECNI by using methane as the moderator gas [8]. When large amounts of oxygen were added to methane, the oxygen addition-induced dechlorination of PCBs was not regioselective [9]. Under these latter conditions, it is difficult to assign unequivocally a reaction mechanism due to the variety of reactants present in the source. Other

Address reprint requests to Dr. F. Lépine, Institut Armand-Frappier, 531 des Prairies Blvd., Laval, Québec, Canada H7N 473. researchers have used a pulsed electron beam high pressure mass spectrometer to obtain reaction rate constants for a few chloroaromatic anions with oxygen [10]. The present work uses tandem mass spectrometry to study the formation of these $[\mathrm{M}+\mathrm{O}-\mathrm{Cl}]$ ions from 10 chloroaromatic compounds by selection of the molecular radical anion and reaction of it with oxygen in the collision cell.

\section{Materials and Methods}

The PCB congeners studied are identified by their IUPAC number and were purchased from Analabs (Norwalk, CT). These congeners are $101\left(2,2^{\prime}, 4,5,5^{\prime}-\right.$ $\left.\mathrm{Cl}_{5}\right), 118\left(2,3^{\prime}, 4,4^{\prime}, 5-\mathrm{Cl}_{5}\right), 146\left(2,2^{\prime}, 3,4,6,6^{\prime}-\mathrm{Cl}_{6}\right), 153$ $\left(2,2^{\prime}, 4,4^{\prime}, 5,5^{\prime}-\mathrm{Cl}_{6}\right), \quad \mathbf{1 8 0}\left(2,2^{\prime}, 3,4,4^{\prime}, 5,5^{\prime}-\mathrm{Cl}_{7}\right), \quad 194$ $\left(2,2^{\prime}, 3,3^{\prime}, 4,4^{\prime}, 5,5^{\prime}-\mathrm{Cl}_{8}\right), 200\left(2,2^{\prime}, 3,3^{\prime}, 4,5^{\prime}, 6,6^{\prime}-\mathrm{Cl}_{8}\right)$, and 209 (decachlorobiphenyl). Pentachlorobenzene (pheCl5) and hexachlorobenzene (pheCl6) were purchased from Aldrich Chemical Co. (St. Louis, MO). All the chloroorganics were dissolved in Accusolv ${ }^{\circledR}$ grade cyclohexane (Anachemia, Ville St-Pierre, Canada). The chloroorganic solutions were mixed in various proportions so that the intensities of the molecular ions roughly were equal for most compounds. Final concentrations of the chloroaromatics were $5 \mathrm{ng} / \mathrm{mL}$ for 209 , 200, 194, and 180, $400 \mathrm{ng} / \mathrm{mL}$ for $153,1 \mu \mathrm{g} / \mathrm{mL}$ for 146, 118, 101, and pheCl6, and $2 \mu \mathrm{g} / \mathrm{mL}$ for pheCl5. The mixture was analyzed by gas chromatography by using a Fisons 8060 (Fisons, Manchester, UK) equipped with a $25-\mathrm{m}$ HP-5 column (0.2-mm-i.d., $0.32-\mu \mathrm{m}$ film 
thickness). The column temperature was programmed from 100 to $210{ }^{\circ} \mathrm{C}$ at $20^{\circ} \mathrm{C} / \mathrm{min}$, then to $280{ }^{\circ} \mathrm{C}$ at 8 ${ }^{\circ} \mathrm{C} / \mathrm{min}$, and finally to $310^{\circ} \mathrm{C}$ at $20^{\circ} \mathrm{C} / \mathrm{min}$ and held at $310^{\circ} \mathrm{C}$ for $3 \mathrm{~min}$.

The experiments were performed in negative ion chemical ionization mode by using a VG Quattro II (Fisons) with methane as the moderator gas. Source pressure and temperature were, respectively, $1 \times 10^{-4}$ mbar and $100^{\circ} \mathrm{C}$. Oxygen $(99.6 \%$; Air Products, LaSalle, Canada) was used as the collision gas. All data acquisitions were performed with a 54-u window selected to include the ions of interest. All experiments were performed in duplicate.

\section{Results and Discussion}

The first experiment consisted of evaluation of the relative transmission of the molecular ions with and without oxygen in the collision cell. Table 1 presents the transmission percentage of one member of the molecular ion cluster with an oxygen pressure of $1.0 \times$ $10^{-3} \mathrm{mbar}$ in the collision cell. Under these conditions, the perfluorotributylamine spectrum was reduced to $25 \%$ of its original intensity. The molecular ions selected are those that were used in the $M-21 / M-19$ ratio determination experiment described in the following text.

The data in Table 1 show that there is a correlation between the number of chlorines on the aromatic ring and the transmission of these ions through the collision cell. The lower chlorinated compounds 101, 118, 146, and 153 seem to interact more with oxygen than the higher chlorinated 180, 194, 200, and 209. Moreover, this interaction is not related to the mass or the size of the molecules, as the pentachloro- and hexachlorobenzene have transmission yields similar to those of the most highly chlorinated PCBs.

There are many interactions possible between organochlorine radical anions and $\mathrm{O}_{2}$. The first reaction (eq 1) involves formation of a radical intermediate that loses $\mathrm{OCl}^{-}$to produce the $[\mathrm{M}+\mathrm{O}-\mathrm{Cl}]$ ions [4]:

$$
\mathrm{ArCl}_{n}^{-\cdot}+\mathrm{O}_{2} \rightarrow \mathrm{ArO}_{2} \mathrm{Cl}_{n}^{-\cdot} \rightarrow \mathrm{ArOCl}_{n-1}+\mathrm{OCl}^{*}
$$

Charge transfer is another possible reaction:

$$
\mathrm{ArCl}_{n}^{-\cdot}+\mathrm{O}_{2} \rightarrow \mathrm{ArCl}_{n}+\mathrm{O}_{2}^{-*}
$$

Simple fragmentation of the radical anion through collision-induced dissociation is also possible:

$$
\begin{aligned}
& \mathrm{ArCl}_{n}^{-\cdot} \rightarrow \mathrm{ArCl}_{n-1}^{-}+\mathrm{Cl}^{-} \\
& \mathrm{ArCl}_{n}^{-\cdot} \rightarrow \mathrm{ArCl}_{n-1}^{-}+\mathrm{Cl}^{-}
\end{aligned}
$$

Fragmentation of a nominal $\mathrm{ArO}_{2} \mathrm{Cl}_{n}^{-\cdot}$ intermediate also has been proposed [10]:

$$
\mathrm{ArO}_{2} \mathrm{Cl}_{n}^{-\cdot} \rightarrow \mathrm{ArO}_{2} \mathrm{Cl}_{n-1}^{\cdot}+\mathrm{Cl}^{-}
$$

The precursor ions within the molecular ion cluster were selected for an experiment designed to determine whether a kinetic isotope effect could be detected in the dechlorination reactions, because significant chlorine isotope effects have been observed for many chloroaromatic compounds in mass spectrometry [11]. These ions then were used as precursor ions throughout this study. The precursor ions chosen were those that produced the highest $M-21$ intensities among their daughter ions, to get the best precision for the calculation of the $M-21 / M-19$ ratio. High intensity for the $M-21$ daughter ion is important because this ion, which arises from the loss of ${ }^{37} \mathrm{Cl}$ from the precursor ion, normally is less intense for most precursor ions within the molecular ion cluster than the $\mathrm{M}-19$ ion that is produced by the loss of a ${ }^{35} \mathrm{Cl}$. The $\mathrm{M}-21$ / $\mathrm{M}-19$ ratio for the $[\mathrm{M}+\mathrm{O}-\mathrm{Cl}]$ ions should be identical to the ${ }^{37} \mathrm{Cl} /{ }^{35} \mathrm{Cl}$ ratio of the precursor ion if the dechlorination reaction is not affected by an isotope effect due to the departing chlorine. To get high

Table 1. Percentage transmission and ${ }^{37} \mathrm{Cl} /{ }^{35} \mathrm{Cl}$ content of the precursor ions and of the $[\mathrm{M}+\mathrm{O}-\mathrm{Cl}]$ ions of various chloroaromatics ${ }^{\mathrm{a}}$

\begin{tabular}{ccccc}
\hline Compound & $\begin{array}{c}\text { Percentage } \\
\text { transmission }\end{array}$ & $\begin{array}{c}\text { Precursor } \\
\text { ion }\end{array}$ & $\begin{array}{c}{ }^{37} \mathrm{Cl} /{ }^{35} \mathrm{Cl} \\
\text { in precursor }\end{array}$ & $\begin{array}{c}\mathrm{M}-21 / \mathrm{M}-19^{\mathrm{b}} \\
\text { in }[\mathrm{M}+\mathrm{O}-\mathrm{Cl}]\end{array}$ \\
\hline \hline PheCl5 & $22(2.8)^{\mathrm{c}}$ & $252(\mathrm{M}+4)$ & $2 / 3$ & $0.66(0.014)$ \\
PheCl6 & $39(3.8)$ & $286(\mathrm{M}+4)$ & $2 / 4$ & $0.50(0.00)$ \\
101 & $4.1(1.0)$ & $328(\mathrm{M}+4)$ & $2 / 3$ & $0.66(0.02)$ \\
$\mathbf{1 1 8}$ & $8.3(1.8)$ & $328(\mathrm{M}+4)$ & $2 / 3$ & $0.67(0.00)$ \\
$\mathbf{1 4 6}$ & $11(2.1)$ & $362(\mathrm{M}+4)$ & $2 / 4$ & $0.50(0.05)$ \\
$\mathbf{1 5 3}$ & $9.3(1.8)$ & $396(\mathrm{M}+4)$ & $2 / 4$ & $0.50(0.00)$ \\
$\mathbf{1 8 0}$ & $20(4.9)$ & $396(\mathrm{M}+4)$ & $2 / 5$ & $0.39(0.00)$ \\
194 & $33(5.0)$ & $432(\mathrm{M}+6)$ & $3 / 5$ & $0.58(0.01)$ \\
$\mathbf{2 0 0}$ & $18(2.6)$ & $432(\mathrm{M}+6)$ & $3 / 5$ & $0.58(0.01)$ \\
$\mathbf{2 0 9}$ & $58(8.4)$ & $500(\mathrm{M}+6)$ & $3 / 7$ & $0.44(0.00)$ \\
\hline
\end{tabular}

Oxygen pressure, $1 \times 10^{-3}$ mbar; collision energy, $5 \mathrm{eV}$

${ }^{b}$ Ratio of the measured intensities of the $M-21$ and $M-19$ ions.

'Numbers in parentheses are the standard deviation of the duplicate. 
intensities for the $M-21$ ions, two conflicting parameters must be balanced. The precursor ion selected within the molecular ion cluster must be as intense as possible and the ${ }^{37} \mathrm{Cl} /{ }^{35} \mathrm{Cl}$ ratio of the precursor ion must be as high as possible also. The $\mathrm{M}-19$ and $M-21$ intensities will depend on the product of these two values. For example, for any compound that contains six chlorines, the most intense ion of the molecular cluster is the $\mathrm{M}+2$ ion, but the ${ }^{37} \mathrm{Cl} /{ }^{35} \mathrm{Cl}$ ratio of this ion is only $0.2\left(1^{37} \mathrm{Cl} / 5^{35} \mathrm{Cl}\right)$. The intensity of a $\mathrm{M}-21$ daughter ion produced from the $\mathrm{M}+2$ ion would be smaller than the one produced from the $\mathrm{M}+6$ ion, which is only $34 \%$ as intense as the $\mathrm{M}+2$, but which has a ${ }^{37} \mathrm{Cl} /{ }^{35} \mathrm{Cl}$ ratio of $1.0\left(3^{37} \mathrm{Cl} / 3^{35} \mathrm{Cl}\right)$. The highest $\mathrm{M}-21$ intensity for compounds that contain six chlorines is obtained with the $M+4$ ion, which has $80 \%$ of the intensity of the $\mathrm{M}+2$ and a ${ }^{37} \mathrm{Cl} /{ }^{35} \mathrm{Cl}$ ratio of $0.5\left(2{ }^{37} \mathrm{Cl} / 4{ }^{35} \mathrm{Cl}\right)$. The selected precursor ions for the variously substituted chloroaromatics are listed in Table 1.

Figure 1 shows a typical mass spectrum of the daughter ions of the $m / z 362 \mathrm{M}+4$ radical anion of 153. Reaction 3 may be discounted because no $\mathrm{M}-35$ ions could be observed. The $\mathrm{ArO}_{2} \mathrm{Cl}_{n}^{--}$intermediate at $\mathrm{M}+32$ also could not be detected. The need for a third body to absorb collision or reaction energy and stabilize such a composite reaction complex is well known. Our data do not support or refute the intervention of such an agent, but rather the failure to detect an intact $\mathrm{ArO}_{2} \mathrm{Cl}_{n}^{-}$argues against the possibility that such a complex exists with a half-life that is significant on the time scale of the instrument transit time. The interpretation we make is that with or without the presence of a third body, the complex decomposes immediately into the products of eq 1 . Formation of the $[\mathrm{M}+\mathrm{O}-\mathrm{Cl}]$ ions was very efficient because these ions were often more intense than the precursor ions, as seen in Figure 1.

Table 1 presents the measured $M-21 / M-19$ ratios of the $[\mathrm{M}+\mathrm{O}-\mathrm{Cl}]$ ions of the various chloroorganics and the corresponding ${ }^{37} \mathrm{Cl} /{ }^{35} \mathrm{Cl}$ ratio of their precursor ions. It is clear that these two ratios are identical for each compound and that there is no measurable isotope effect in this dechlorination reaction.

To investigate the first step of reaction 1 , the effect of varying the relative concentration of $\mathrm{O}_{2}$ on the

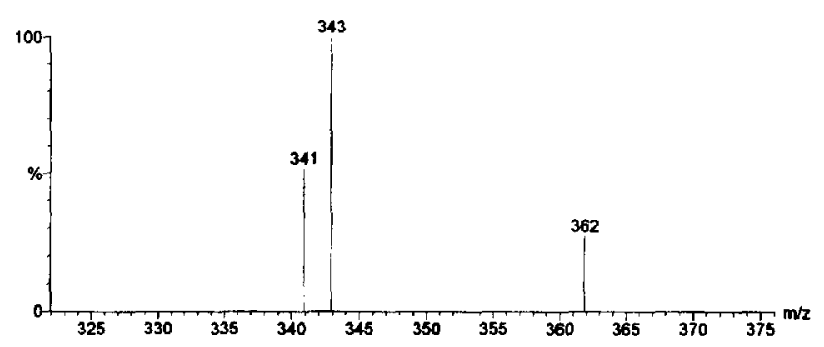

Figure 1. Daughter ion mass spectrum of $\mathrm{m} / \mathrm{z} 362$ of PCB 153 with oxygen in the collision cell $\left(1.0 \times 10^{-3}\right.$ mbar, collision energy $5 \mathrm{eV})$ acquired over the scan range employed $(\mathrm{m} / \mathrm{z}$ $322-376$ ). formation of the $[\mathrm{M}+\mathrm{O}-\mathrm{Cl}]$ ions was investigated. Figure 2 presents the intensities of the $[\mathrm{M}+\mathrm{O}-\mathrm{Cl}]$ (as the sum of the $M-19$ and $M-21$ ions, thick lines, left axis) and their precursor ions (dashed lines, right axis) for various oxygen pressures with a collision energy of $5 \mathrm{eV}$. The $[\mathrm{M}+\mathrm{O}-\mathrm{Cl}]$ ion intensities could not be normalized with respect to their precursor ion for many of the compounds studied because at high $\mathrm{O}_{2}$ pressures the precursor intensities of some compounds fell to zero. For almost every compound, the intensities of the $[\mathrm{M}+\mathrm{O}-\mathrm{Cl}]$ ions increase with increasing oxygen pressure up to a maximum and then decrease. This behavior is probably owing to two factors: (1) increased production of the $[\mathrm{M}+\mathrm{O}-\mathrm{Cl}]$ ions with increasing oxygen pressure and (2) a reduced ion transmission with increasing pressures. For every compound, a decrease of the intensity of the precursor ion of approximately 2 orders of magnitude was observed within this pressure range. The intensities of the $[\mathrm{M}+$ $\mathrm{O}-\mathrm{Cl}$ ] ions for a given compound were directly proportional to the amount of material injected.

Figure 2 shows that the oxygen pressure at which the $[\mathrm{M}+\mathrm{O}-\mathrm{Cl}]$ ion intensities maximize depends on the extent of chlorine substitution on the aromatic rings. The maxima for the penta- and hexachlorobiphenyls are at $1.0 \times 10^{-3}$ mbar, whereas for the hepta-, octa-, and decachlorobiphenyl and for pentachlorobenzene they are at $3.0 \times 10^{-3}$ mbar. For hexachlorobenzene the highest value is at $6 \times 10^{-3} \mathrm{mbar}$, which probably reflects the relative affinity of the radical anions for oxygen, the more highly substituted aromatics are more stable and less reactive than the lesser. This is also consistent with the general trend toward lower $[\mathrm{M}+\mathrm{O}-\mathrm{Cl}] / \mathrm{M}$ ratio for the more substituted chloroaromatics. This lower ratio could explain the difference in the transmission of the precursor ions observed in Table 1 , in which the less chlorinated compounds have a lower transmission than the more chlorinated ones, presumably because the former react more readily with oxygen than do the latter. In work with a pulsed electron beam high pressure mass spectrometer, Knighton et al. [10] also observed that pentachlorobenzene was more reactive than hexachlorobenzene toward oxygen.

The same daughter ion experiment was repeated for the same ions with the $\mathrm{O}_{2}$ pressure fixed at $3.0 \times 10^{-3}$ mbar but with increasing collision energies. This value corresponds, with this instrument, to the lower limit of the pressure range $\left(3.0 \times 10^{-3}\right.$ to $\left.3.0 \times 10^{-2} \mathrm{mbar}\right)$ in which the ions undergo sufficient collisions in the cell to be thermalized. Because we are so close to that limit, the collision energy indicated may be slightly different than the true collision energy. Consequently, the collision energies presented in Figure 3 are the indicated collision energies. Because any residual energy due to incomplete thermalization of the transmitted ions also could affect the efficiency of their transmission through the cell, their intensities may be slightly overestimated at the higher collision energies. 

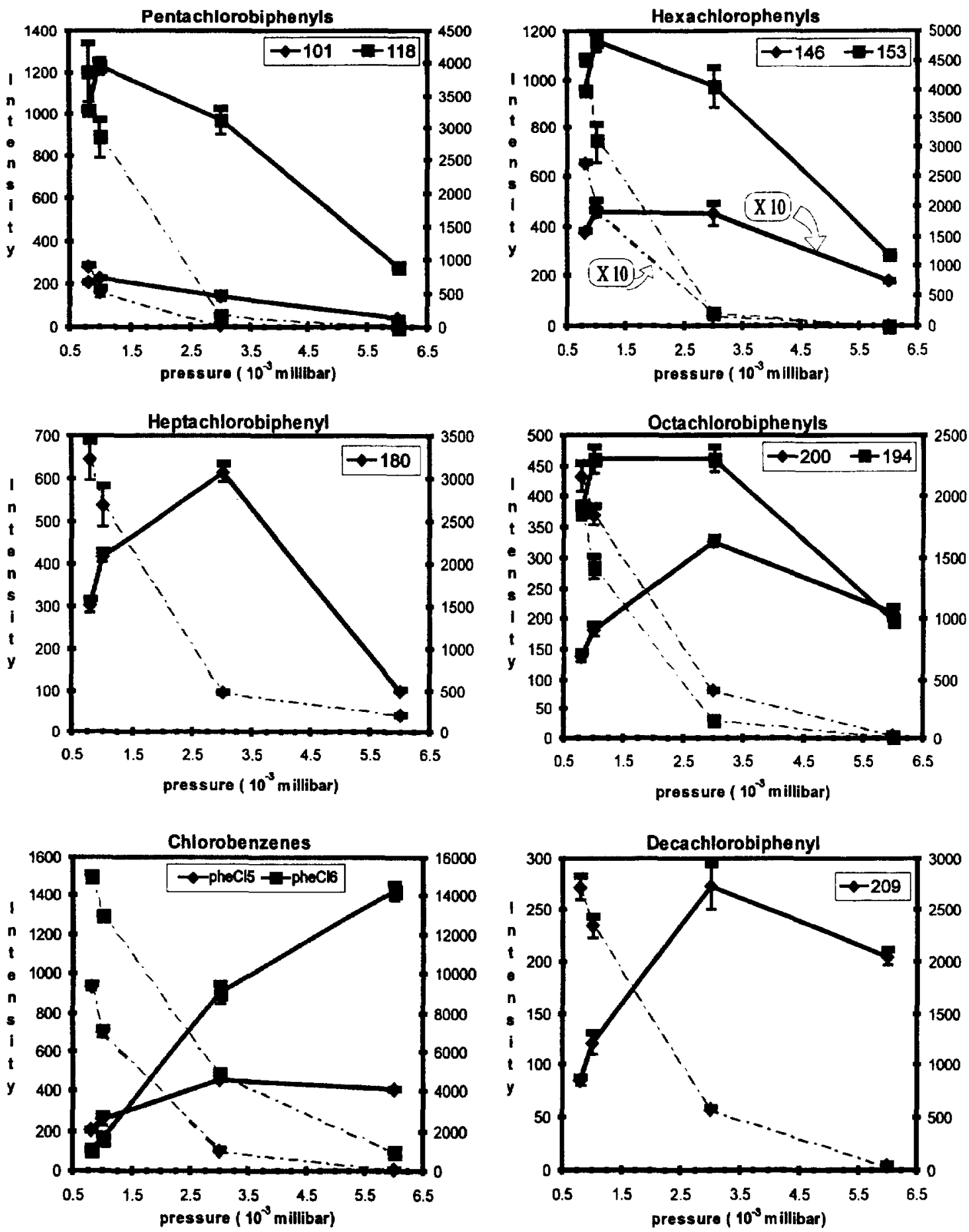

Figure 2. Variation of the sums of the integrated peak areas of the $M-19$ and $M-21$ ions for various chloroaromatic compounds with oxygen pressure in the collision cell. Collision energy, $5 \mathrm{eV}$. The left axis and thick lines are the intensities of the $[\mathrm{M}+\mathrm{O}-\mathrm{Cl}]$ ions; the right axis and dashed lines are the intensities of the precursor ions. Numbers on the curves refer to specific PCB congener.

The 146 intensities were multiplied by 10 .

Figure 3 presents the $[\mathrm{M}+\mathrm{O}-\mathrm{Cl}]$ (thick lines, left axis) and their precursor ion (dashed lines, right axis) intensities versus collision energy. The intensities of the precursor ions for 101, 118, 146, and 153 decrease with increasing collision energies, whereas the intensi- ties of the other chloroaromatics generally increase at 5 and $10 \mathrm{eV}$ to decrease rapidly at $15 \mathrm{eV}$. This transient increase in precursor ion intensities observed at intermediate collision energies could be attributed to better focusing of these ions at these energies. This also could 
explain the slight increase in the $[\mathrm{M}+\mathrm{O}-\mathrm{Cl}$ ion intensities observed at these energies for $\mathbf{2 0 0}$ and decachlorobiphenyl. Nevertheless, for every compound, the $[\mathrm{M}+\mathrm{O}-\mathrm{Cl}]$ intensities become very small at $15 \mathrm{eV}$.
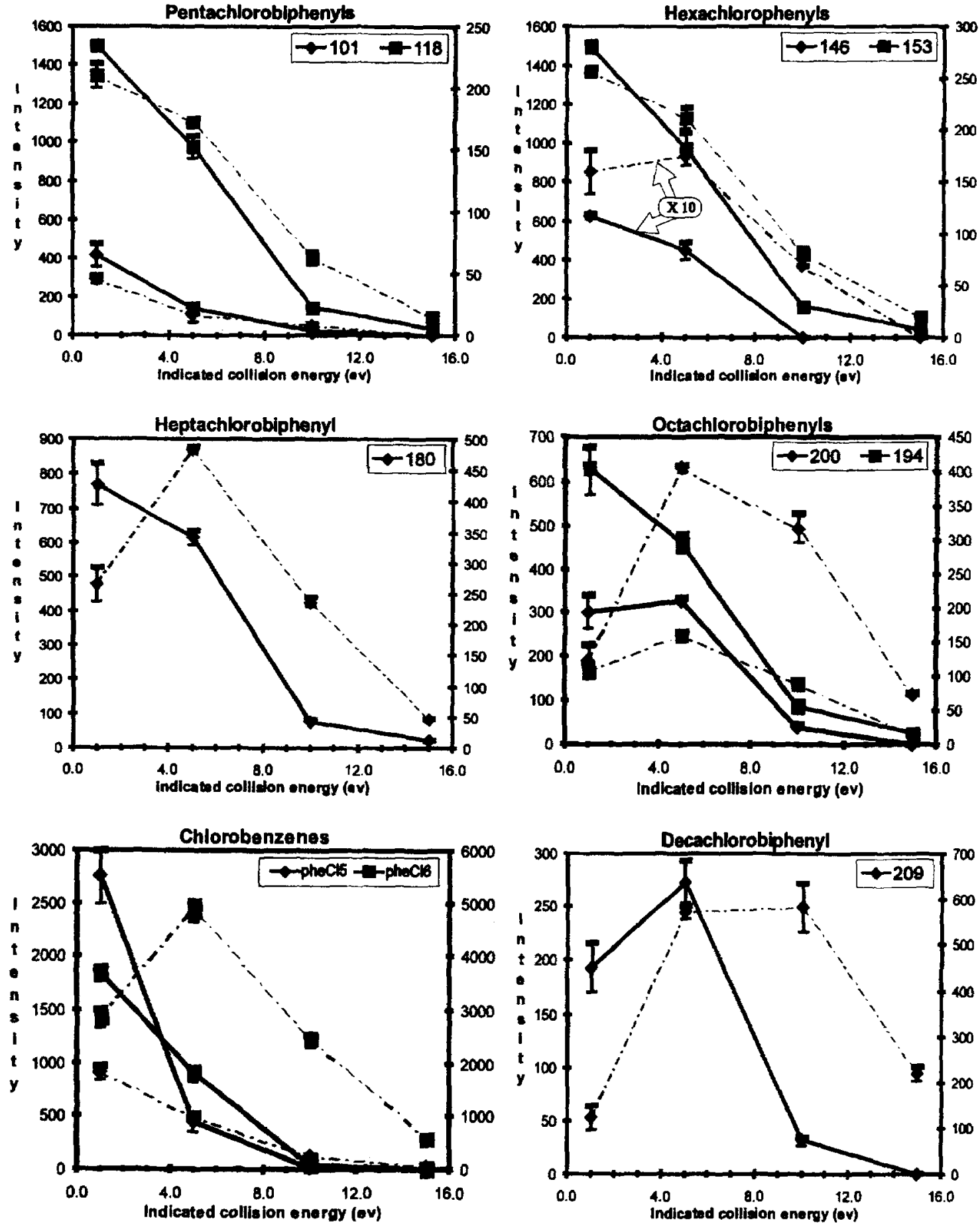

Figure 3. Variation of the sums of the intensities of the $M-19$ and $M-21$ ions of various chloroaromatic compounds with indicated collision energy. Oxygen pressure, $3.0 \times 10^{-3} \mathrm{mbar}$. The left axis and thick lines are the intensity of the $[\mathrm{M}+\mathrm{O}-\mathrm{Cl}]$ ions; the right axis and dashed lines are the intensities of the precursor ions. Numbers on the curves refer to specific PCB congener. The 146 intensities were multiplied by 10 . 
ion (Figure 3) and an increase of $\mathrm{O}_{2}^{-}$(Figure 4, thick lines, left axis) and $\mathrm{Cl}^{-}$(Figure 4, dashed lines, right axis) at collision energies higher than $10 \mathrm{eV}$.

According to the literature, reactions 4 and 5 both contribute to formation of $\mathrm{Cl}^{-}[10]$. To test the contri- bution of reaction 4 to the production of $\mathrm{Cl}^{-}$at higher energies, argon was used at $3 \times 10^{-3} \mathrm{mbar}$ as the collision gas instead of oxygen. These results, presented in Table 2, show that at $5 \mathrm{eV}$, the intensities of the $\mathrm{Cl}^{-}$ions are comparable and reasonably indepen-
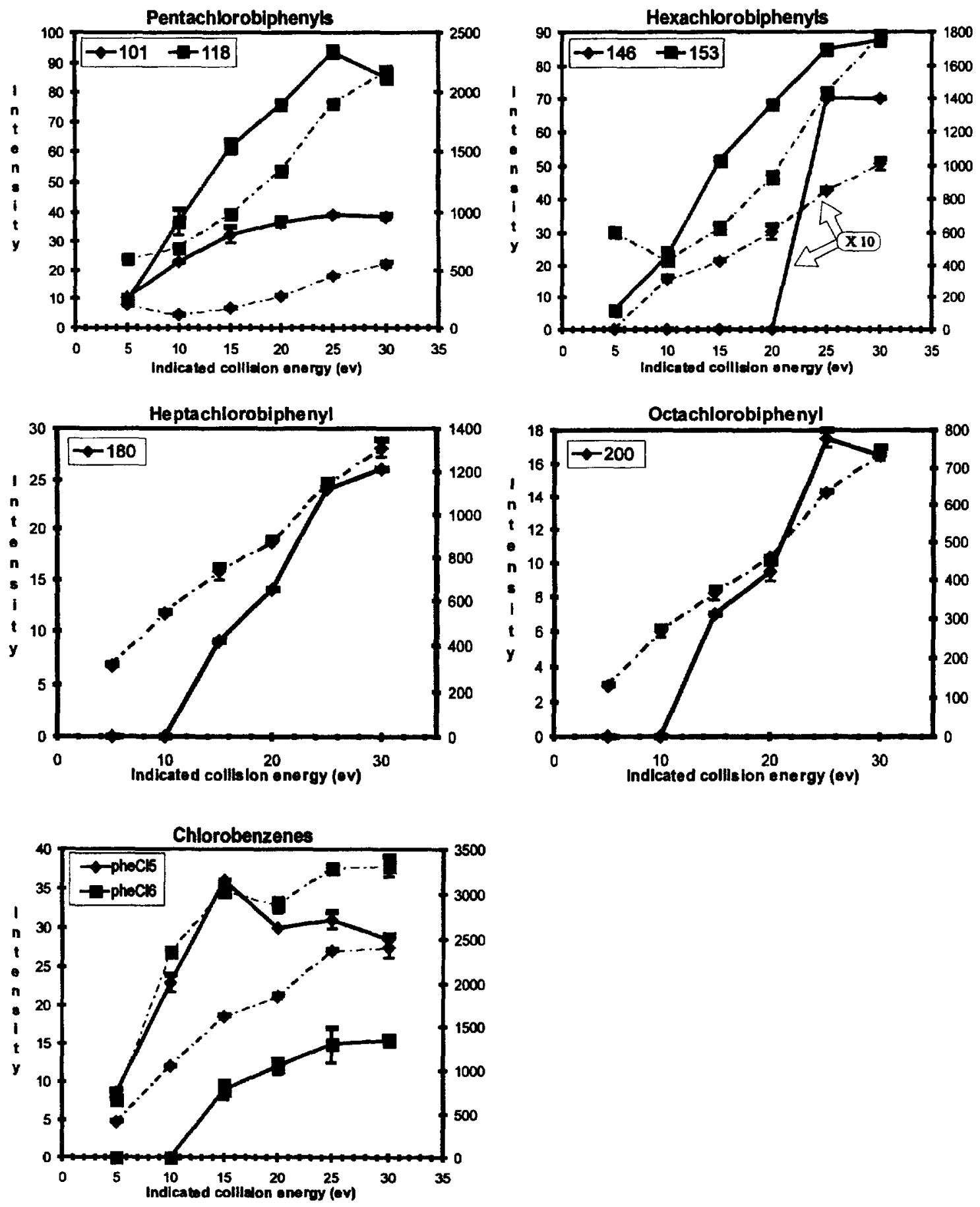

Figure 4. Variation of the $\mathrm{O}_{2}^{-\cdot}$ daughter ion intensity for various chloroaromatic compounds with indicated collision energies. Oxygen pressure, $3.0 \times 10^{-3}$ mbar. The left axis and thick lines are the intensities of the $\mathrm{O}_{2}^{-\cdot}$ ion; the right axis and dashed lines are the intensities of the $\mathrm{Cl}^{-}$ion. Numbers on the curves refer to specific PCB congener. The 146 intensities were multiplied by 10. 
Table 2. Combined intensities of the ${ }^{37} \mathrm{Cl}$ and ${ }^{35} \mathrm{Cl}$ ions divided by the intensity of a selected molecular ion ${ }^{a}$ for various chloroaromatic compounds using argon or oxygen in the collision cell $^{\mathrm{b}}$

\begin{tabular}{ccc}
\hline Compounds & Argon & Oxygen \\
\hline \hline PheCl5 & $1.06(0.16)^{c}$ & $0.90(0.05)$ \\
PheCl6 & $0.43(0.01)$ & $0.73(0.03)$ \\
118 & $1.95(0.08)$ & $0.65(0.04)$ \\
153 & $0.57(0.08)$ & $0.62(0.06)$ \\
180 & $0.62(0.02)$ & $0.51(0.03)$ \\
194 & $0.32(0.01)$ & $0.38(0.01)$ \\
200 & $0.49(0.06)$ & $0.28(0.02)$ \\
209 & $0.39(0.02)$ & $0.27(0.03)$ \\
\hline
\end{tabular}

a The molecular ions selected are those listed in Table 1.

${ }^{b}$ Collision gas pressure, $3 \times 10^{-3}$ mbar; collision energy, $5 \mathrm{eV}$.

"Numbers in parentheses are the standard deviation.

dent of the nature of the collision gas. Thus, at collision energies higher than $5 \mathrm{eV}$, the proportion of $\mathrm{Cl}^{-}$generated by simple CID is likely to be important.

Reaction 2 was investigated by monitoring $\mathrm{O}_{2}^{-\cdot}$ in the daughter ion mode with the same precursor ions while collision energies were varied. Figure 4 shows the variation of the intensity of the $\mathrm{O}_{2}^{-\cdot}$ ion with collision energies at $3.0 \times 10^{-3}$ mbar. All observations show increases with increasing collision energy, to reach maxima at about $25 \mathrm{eV}$. More important than the increase of intensities of this ion with increasing collision energy, which could be influenced by variations in the transmission of this ion through the cell depending on the energy imparted to the precursor ions, is the correlation of the absolute $\mathrm{O}_{2}^{-\cdot}$ intensities with the number of substituents. The more chlorinated compounds generate smaller $\mathrm{O}_{2}^{-\cdot}$ intensities than the lesser chlorinated ones. No data are presented for 194 and decachlorobiphenyl in Figure 4 because the $\mathrm{O}_{2}^{-\cdot}$ intensities were too small to be significant.

Figure 4 demonstrates that reaction 2 occurs and that, for the same collision energy, the intensities of $\mathrm{O}_{2}^{-\cdot}$ are larger for the less chlorinated aromatics than for the more chlorinated ones, which is likely due to the relative electron affinities of the various species involved. The electron affinity of pentachlorobenzene was determined by Knighton et al. [10] to be $0.7 \mathrm{eV}$ versus $1.0 \mathrm{eV}$ for hexachlorobenzene and $0.4 \mathrm{eV}$ for oxygen. For a compound that has a greater electron affinity than oxygen, the equilibrium will favor the reverse reaction 2 and this can explain the lower intensities of $\mathrm{O}_{2}^{--}$observed for hexachloro- than for pentachlorobenzene. Because electron affinity is related to the number of chlorine substituents (as seen for the chlorobenzenes), the more chlorinated PCBs, along with the penta- and hexachlorobenzene, are likely to have higher electron affinities and will generate lower $\mathrm{O}_{2}^{-}$intensities than the lesser chlorinated PCBs. Because penta- and hexachlorobenzene are more electronegative than oxygen [10], the $\mathrm{O}_{2}^{-\cdot}$ found in these experiments likely is produced in an endothermic reaction and kinetically controlled conditions probably apply.

\section{Conclusion}

The molecular anions of PCBs and chlorobenzenes with various levels of chlorination react efficiently with oxygen in the collision cell of a triple quadrupole. The nature of the chloroaromatic, mostly the extent of chlorine substitution, is a key parameter that controls the formation of $[\mathrm{M}+\mathrm{O}-\mathrm{Cl}]$ ions and the extent of a competing charge-transfer reaction. Simple collision induced dissociation of the molecular anion also was observed. The dechlorination reaction that gives rise to the $[\mathrm{M}+\mathrm{O}-\mathrm{Cl}]$ ion is not affected by a measurable chlorine isotope effect.

\section{Acknowledgments}

This work was supported by grants from the Natural Sciences and Engineering Research Council of Canada and from the Medical Research Council of Canada.

\section{References}

1. Biros, F. J.; Dougherty, R. C.; Dalton, J. Org. Mass Spectrom. 1971, 6, 1161.

2. Levonowich, P. F.; Tannenbaum, H. P.; Dougherty, R. C. I. Chem. Soc. Chem. Commum. 1975, 597.

3. Stemmlex, E. A.; Hites, R. A.; Arbogast, B.; Budde, W. L.; Deinzer, M. L.; Dougherty, R. C.; Eichelberger, J. W.; Foltz, R. L.; Grimm, C.; Grimsrud, E. P.; Sakashita, C.; Sears, L. J. Anal. Chem. 1988, 60, 781.

4. Dzidic, I.; Carroll, D. I.; Stillwell, R. N.; Horning, E. C. Anal. Chem. 1975, 47, 1308.

5. Fung, D.; Boyd, R. K.; Safe, S.; Chittim, B. G. Biomed. Mass Spectrom. 1985, 12, 247.

6. Hass, R. J; Friesen, M.; Hoffman, M. K. Org. Mass Spectrom. $1979,14,9$.

7. Guevremont, R.; Yost, R. A.; Jamieson, W. D. Biomed. Environ. Mass Spectrom. 1987, 14, 435.

8. Lépine, F. L.; Milot, S.; Reimer, M. L. J.; Mamer, O. A. Org. Mass Spectrom. 1994, 29, 133.

9. Lépine, F. L.; Milot, S.; Mamer, O. A. J. Am. Soc. Mass Spectrom. 1996, 7, 66.

10. Knighton, W. B.; Bognar, J. A.; Grimsrud, E. P. J. Mass Spectrom. 1995, 30, 557.

11. Zakett, D.; Flynn, G. A.; Cooks, R. G. J. Phys. Chem. 1978, 82, 2359. 